\title{
The Space Cruise over the Route "Earth-Mars-Earth"
}

\author{
Alexander Rubinraut \\ Design Office, Expeditions to Planets (EXPPLANET), Munich, Germany \\ Email: rubinraut32@mail.ru
}

How to cite this paper: Rubinraut, A. (2018) The Space Cruise over the Route "Earth-Mars-Earth". Advances in Aerospace Science and Technology, 3, 20-47. https://doi.org/10.4236/aast.2018.32003

Received: April 2, 2018

Accepted: June 25, 2018

Published: June 28, 2018

Copyright $\odot 2018$ by author and Scientific Research Publishing Inc. This work is licensed under the Creative Commons Attribution International License (CC BY 4.0).

http://creativecommons.org/licenses/by/4.0/

\begin{abstract}
A project of the space cruise over the route "Earth-Mars-Earth" is considered. Design of electric rocket train, whose energy source is a semiconductor solar panel and a superconducting electrorocket engine (MARS) of new design is used as a mover, is developed. The concept of the cruise, which allows to reduce time of interorbital flight in twice, owing to refueling with working body on orbit of Mars, is developed. Development of the space locomotive with 4 MARS engines rated at $600 \mathrm{~kW}$ in which nitrogen is used as working substance, was being carried out. A new design of takeoff-landing capsule, in which cabin can be placed 10 space tourists, is developed. The studies carried out on the mathematical model, which takes into account the changing of power provided by onboard power plant, depending on the distance from the Sun, has shown that cruise may be done within 77 days including the stay of tourists on the Martian surface during 7 days. The project provides for implementation three cruises on the surface of Mars and 15 cruises on the lunar surface during two years with total cost of 2.2 billion dollars.
\end{abstract}

\section{Keywords}

Space Cruise, Electrorocket Train, Superconducting Electrorocket Engine MARS, Space Locomotive with Solar Battery

\section{Introduction}

Since the day of first docking of spacecrafts, artificial Earth satellites had passed already 50 years.

The spacecrafts "Soyuz 186" (Union 186) and "Soyuz 187" (Union 187), launched from the space launch facility Baikonur, on the 30 September 1967 have gone into circumterrestrial orbit. Then their approaching and the docking had been carried out in automatic mode. 
Unfortunately, the chief designer of the "unions" S.P. Korolev did not live to see this day. On January 14, 1966, he had tragically died during the surgery at the Kremlin hospital.

The significance of the first docking in astronautics history can scarcely be overestimated.

The docking of the Soyuz spacecrafts had given the green light for the construction of the space trains, the idea creation of which belongs to K.E. Tsiolkovsky. As it is known, the first space train called "Apollo" had been designed and built by NASA under the leadership of Chief Designer Werner von Braun. On July 10, 1969 Apollo had started the path along the route "the orbit of Earth-the orbit of the Moon". The space train had a locomotive, in the hull of which a chemical rocket engine, tanks with fuel and oxidizer and cabin for the crew consisting of three astronauts were located. In the nasal part of the locomotive a docking unit was located with the help of which towards the locomotive a landing capsule was connected. After going into the Moon orbit, the capsule performed the landing on its surface. After the conclusion of the stay on the Moon, the takeoff of the capsule, its approach and docking with locomotive took place.

The first Moon expedition was the triumphant event of the 20 century. The further step in the development of astronautics should be implementation of expeditions towards planets of the solar system and their satellites.

But in the 21 century the development pace of space technique and technology have significantly declined even in spite of the fact that already to the beginning of the 21 century while using chemical rocket engines, the problem for delivery of large masses into orbit around the Earth was solved. The main reason is the circumstance that due to low magnitude of the specific impulse the chemical rocket engines are not suitable for implementation of interorbital flights. For this purpose electric rocket engines are intended. The greatest tractive force for implementation of jet propulsion creates a magnetoplasma engine (MPE). While running this engine, a discharge is burning between the electrodes and the interaction of flowing current with the magnetic field creates a traction force.

The engine of this type was first developed at Princeton University (USA) and was tested at NASA's Jet Propulsion Laboratory in 1981 [1]. The detailed description of the MPE is given in the works of Professor of Princeton University Edgar Y. Choueriri [2].

But unfortunately the efficiency of the MPE of the known designs is only $50 \%$.

In 2006 the author proposed a new design of MPE with outer superconducting winding, which creates the tangential magnetic field. For this purpose the current in the superconducting winding is directed along the axis of the engine. This allows to increase the efficiency of the engine from $50 \%$ to $95 \%$ [3].

In 2008 the design of reusable spacecraft for flight to Mars was developed. The interorbital flight should be carried out using the electrorocket engine, the landing and take-off from the surface of Mars should be carried out using chemical 
rocket engine [4].

In 2008 the demo model of the spacecraft for flights to Mars was made.

In 2011 the design of a space train for flights towards planets of the solar system was developed. The space train consists of the locomotive on which electrorocket engines and onboard power installation are installed, whereas working substance-hydrogen and oxygen in liquid state are located in a tank-container. The new design of the onboard power installation consisting of a gas nuclear reactor, MHD generator and turbo generator was developed.

For landing and takeoff from the surface of planets and their satellites the design of a takeoff-landing capsule, inside which there is the cabin for astronauts, was developed. The locomotive, the tank-container, and the takeoff-landing capsule are joined on the orbits of the planets of the solar system by means of docking, forming the space train [5].

In 2013, the author has got a patent of Germany for invention "Electric rocket engine for flight on Mars" [6].

In 2014-2016 the projects of carrying out of expeditions towards all the planets of the solar system were developed. For this purpose a technique was proposed and a new design of the interorbital rocket trains was developed. The rocket train is supplemented by a refueller with a tank for working substance. During a preliminary flight the refueller is sent onto orbits of Mars, Venus, Mercury and the working substance is used during return flights of the expeditions [7] [8] [9].

For expeditions towards gas planets in the solar system: Jupiter, Saturn, Uranus and Neptune the design of an stand-alone refueller with working substance was developed, which during preliminary flight is sent towards satellites of these planets: Europe, Titan, Oberon and Triton, which surface is covered with water ice.

Automatic refueller thaws the ice and out of derived water by means of electrolysis produces hydrogen, which after liquefaction is refueled in tanks-containers of the space train [10] [11] [12] [13] [14].

In 2016 a study of the superconducting magnetoplasma rocket engine was carried out.

A mathematical model of electro-mechanical processes occurring in the working chamber was composed. The study had confirmed the effectiveness of the proposed technical solutions. A new design was also proposed, which by means of moving and cooling of cathode allows to increase service time by several times [15] [16].

In recent years, work on the implementation of scientific expeditions towards planets of the solar system was reduced practically to zero due to shortage of funds.

However, in the space field of activity a new direction-space tourism has appeared. The hope arose, that this commercial undertaking will allow the space industry to emerge from stagnation.

And really, a successful entrepreneur, the executive of the company "Space X" 
Mr. Elon Musk, according to the magazine "Space" N 4, 2017, is going to send in 2018 two tourists on the Moon surface.

The author of this work has also decided to contribute to the shaping of this new direction, where scientific expeditions replace the walks of wealthy people who can pay the ticket for travel on the space train.

The aim of the presented work is the development of the project the space cruise along the route the Earth-Mars-Earth.

The cruises on Mars will be carried out by the private companies of space tourism.

Therefore, the cost of the flight becomes the main optimization criterion.

The analysis showed that the most expensive part of the space train is the on-board power plant, consisting of nuclear reactor, MHD generator and turbo generator [7].

The project of a space train, which electrorocket engines get electric power from solar batteries, was considered. In this case, the cost of creating the onboard supply unit is considerably reduced.

Such a decision is not a novelty in the astronautics history. Still in 1988 in the Soviet Union a project of a Martian expedition was developed, in which the power supply unit had consisted of two panels of solar batteries having the size of $200 \times 200 \mathrm{~m}$.

Locomotive of the space train had cylindrical body, in which magnetoplasma the electrorocket engines and tanks with working substance-xenon had been located.

The locomotive was docked to Martian orbital apparatus having mass of $80 \mathrm{t}$. The expedition flight time was 716 days including the stay of two astronauts on the surface of Mars during the 9 days [17].

In this project the space train should be launched into Earth orbit using carrier rocket "Energy". It should be recalled that, under the leadership of Chief Designer V.P. Glushko the carrier rocket "Energy" in the year 1987 had put into Earth orbit the rocket-plane "Buran" having mass of 105 tons.

Since then, it has been almost 30 years. The Soviet Union does not exist already for a long time, but space branch of activity continues to function, and employs a new generation of scientists, engineers and astronauts. Around the Earth revolves the international space station ISS, which serves not only as a laboratory, but also port with moorages for docking of spacecrafts.

With regard to solar battery panels, for years, this area has undergone tremendous changes.

At the recent international exhibition "Solar 2017", which took place in $\mathrm{Mu}$ nich in June 2017, we have witnessed the technical revolution in energetics, which is based on the use of solar battery panels.

The cost of electricity generated by the solar battery panels has declined dozens of times and has become lower than the cost of electricity generated by thermal power plants. 
The efficiency of solar batteries made from silicon has increased. According to the company "Astronergy" the solar battery efficiency has reached 23\% [18].

The company DAS Energy GmbH, Austria has mastered the film technology of solar panel production and had begun mass production of flexible solar panels in the form of long rug Specific weight index of solar battery is $2.5 \mathrm{~kg} / \mathrm{m}^{2}$ [19].

Significant progress is achieved also in the branch of industry of conventional silicon photovoltaic converters.

Solar battery cell based on gallium arsenide, was first used in 1967, during the first flight of the spacecraft "Venus". The main advantage of GaAs batteries-high efficiency, their disadvantage-high cost.

Today on the world market there are the photovoltaic converters of firms Electrolab (United States), Soitec (Germany), Sharp (Japan), Quantum (Russia), etc., which are produced based on the technology of multilayer structures.

The technology three-stage solar cell based on gallium arsenide with germanium as bottom layer is developed, which allow to use the solar energy in the entire range of the spectrum.

The efficiency of the currently manufactured GaAs solar panels reaches $44 \%$ [20].

But it should not be forgotten that while movement of the space train away from the Sun, the light intensity continuously decreases. This circumstance should be taken into account when calculating of solar battery for space train.

\section{The Concept of the Tourist Cruise along the Route "Earth-Mars-Earth"}

In order to formulate the concept of the cruise a mathematical model had been drawn up which allows to compare different technical solutions by means of optimization. As the main criterion of the optimization, the minimum of cost was adopted.

The calculations conducted on the mathematical model have showed that in order to compensate the initial costs due to revenue, the cruises must be continuous.

To conduct cruises it is necessary to create two orbital refueling bases.

The orbital base no.1 should be placed into orbit around Mars, and orbital base no. 2 should be placed onto circumterrestrial orbit.

At these orbital bases the working substance should be kept, which is used in electrical rocket engines of the space train.

The working substance should be kept in the liquid state in tanks having thermal insulation to reduce loss of the working substance because of evaporation.

Delivery of the working substance on the base no. 1 should be performed using an electric locomotive. Delivery of the working substance on the base no. 2 should be carried out using rocket "Falcon X Heavy".

The conducted calculations also showed that the most rationally is to use ni- 
trogen as working substance for electrorocket engines. Density of nitrogen at order higher than of hydrogen, and boiling point-nearly four times higher.

The use of nitrogen significantly reduces the volume of the tanks with working substance, simplifies design of devices, improves the reliability and increases service life. Along with this the cost is significantly reduced.

Liquid nitrogen is also used to support the operation of the superconducting excitation winding of electrorocket engine, superconducting pump and bearing.

To conduct repeated cruises one must refill tanks with fuel (liquid hydrogen) and with oxidant (liquid oxygen) for chemical rocket engine, located in takeoff-landing capsule.

Calculations show that the refueling of the takeoff-landing capsule should be also carried out on the base no. 2. And therefore it is also necessary to place on the base no. 2 the tanks with liquid hydrogen and with liquid oxygen. Delivery of the tanks should be carried out using the carrier rocket "Falcon X".

The cruise along the route the Earth-Mars-Earth is carried out by means of flights of two space trains. The first space train is a freight train, it works automatically and is shown in Figure 1.

The freight space train consists of a space locomotive 1 and a tank-container 2 with working substance. With the help of the freight space train the problem of the constant supply of the base no.1 (on Mars orbit) with reserve working substance (nitrogen), required for movement of the passenger space train, which executes the cruise, is being solved. The design shown in Figure 1, is formed in Earth orbit by means of dockings.

Initially, onto the circumterrestrial orbit the locomotive 1 is being put. The launch is exercised using rocket Delta 4 Heavy. After the launching, the solar battery panels of the locomotive are unfolding (in an automatic mode). The detailed description of the locomotive design is given below.

After automatic assemble of the solar battery panels of the locomotive, the electric rocket engines 3 are being switched on and the locomotive readiness to operate is being tested.

By means of the second launch the tank-container 2 with working substance is being put into the same orbit around the Earth by means of carrier rocket Delta 4 Heavy.

The electric locomotive 1 in automatic mode approaches to the tank-container 2 and using the docking unit 4 the docking is being carried out.

The freight train (Figure 1) is ready for orbital flight.

The electrical rocket engines 3 are switched on and the space train (Figure 1) starts the movement towards the planet Mars with acceleration. In two days, the train overcomes the attraction of the Earth and becomes a Sun satellite. After reaching the escape velocity it comes into the calculated trajectory of movement. The calculation of the movement trajectory towards Mars was conducted using the astrodynamic program, which is based on solution of Newton task about the motion of artificial bodies in a gravitational field of the planetary solar system 


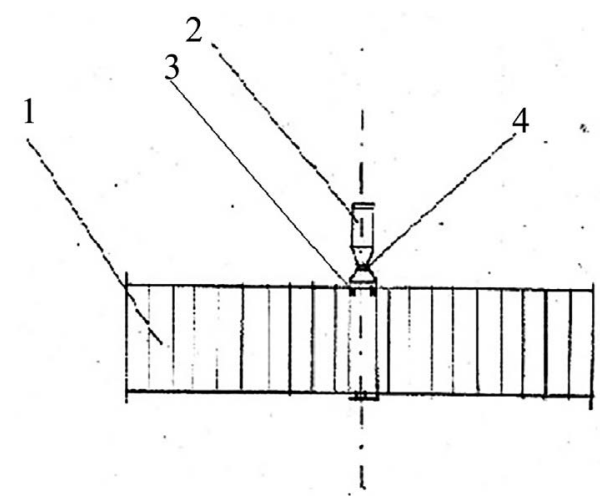

Figure 1. Freight space train.

[21]. The acceleration of the space train continues 10 days. At the end of the acceleration period the speed of the train reaches $30 \mathrm{~km} / \mathrm{sec}$.

Then the electric rocket engines are being switched off and the train moves at constant speed by inertia. In 130 days the train No. 1 flies up to the planet Mars and the train braking begins. In order to carry out the braking, it is necessary to reverse the direction of thrust vector on $180^{\circ}$.

To do this, two of the four engines are switched off and the train commits the necessary maneuver, while continuing to move by inertia to the planet Mars.

After 180-degree turn the braking of the train begins, which lasts 10 days.

Train speed reaches $3.6 \mathrm{~km} / \mathrm{s}$ and it enters into orbit around Mars. This orbit becomes the stay seat of the base no.1. The corresponding command is given and the splitting of the locomotive 1 and tank-container 2 with working substance is carried out (with the help of docking unit 4). The electric rocket 3 engines are switched on. The locomotive makes the maneuver and moves away from the tank-container 2. The tank-container 2 remains on the orbit in anticipation of the arrival of the passenger train No. 2, on which the tourists commit the cruise.

Afterwards 150 days since the beginning of movement the locomotive of the train no. 1 continues to perform its supply mission. Now it must move from the orbit of Mars (base no. 1) into Earth orbit (base no. 2).

The electrical rocket engines are switched on and the locomotive begins to increase the speed. 5 hours later it reaches the escape velocity and leaves Mars orbit. 10 days later, when the speed is $110 \mathrm{~km} / \mathrm{sec}$, the acceleration comes to an end and the locomotive of the train no.1 goes over to the mode of inertial movement, which lasts 40 days.

Then the locomotive carries out the maneuver with 180 degree turn. The electric rocket engines 3 are being switched over on the braking mode. 10 days later the locomotive speed drops to $8 \mathrm{~km} / \mathrm{s}$ and it goes into the basic circular orbit around the Earth. In such way the full cycle of interorbital movement of the freight space train, which lasts 210 days, ends.

By the time of the arrival of the locomotive at the base orbit no. 2 , the base 
should be ready for ensuring the further movement of the freight space train.

For this purpose two tank-containers with the working substance-nitrogen, are delivered onto the base orbit with the help of carrier rocket "Falcon $\mathrm{X}$ Heavy". The first tank-container is intended for refilling the locomotive itself and the second tank-container-for fulfillment the main function of the freight space train.

While maneuvering by using electric rocket engine 3 , the locomotive docks with the first tank-container, as shown in Figure 1. After the docking the cryogenic pump of the locomotive is switched on, and liquid nitrogen is being pumped into the tank, located inside the locomotive. After the refuelling the locomotive pushes off from the first tank-container and moves towards the second tank-container. Then approaching, moorage and docking of the locomotive with the second tank-container takes place.

Now the freight space train no. 1 (Figure 1) is ready to repeat the cycle of delivery onto Mars orbit tank-container with working substance.

The second space train No. 2, which carries out the movement with tourists during the cruise Earth-Mars-Earth is the passenger train. It can be operated as in automatic mode as well in manual control mode. This train must be controlled by "a space driver"-high professional astronaut, specialist in the field of space technics control.

The passenger train is shown at Figure 2.

It consists of two locomotives 1 and 2, united by means of the docking unit 6 .

As the energy source for the space train, the photoelectric converter of solar energy into electricity is used. As mover the electrorocket engine is used.

Such a space train can be rightfully called the electric rocket train.

During the cruise, passengers (tourists) are located in takeoff-landing capsule 3.

The takeoff-landing capsule 3 is fitted with a hydrogen-oxygen chemical rocket engine 7, which allows to carry out landing on the surface of Mars, takeoff from the surface of Mars and entering into Mars orbit. Chemical rocket engine 7

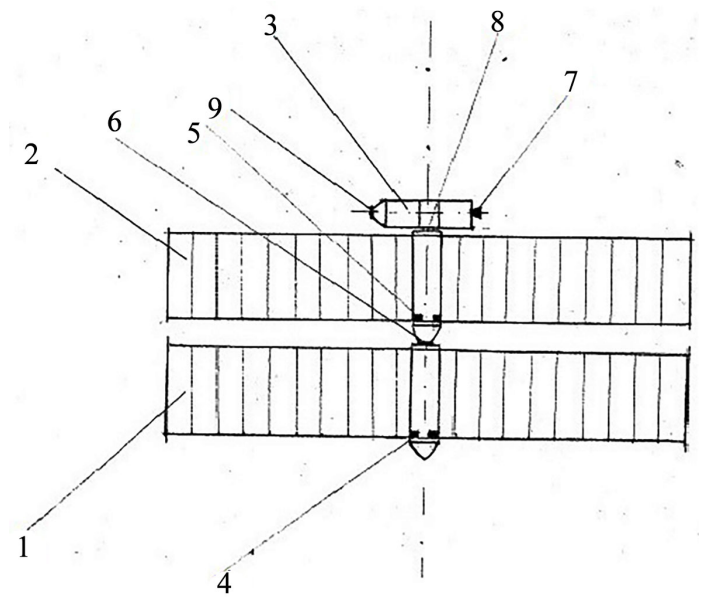

Figure 2. Passenger space train. 
gives also the possibility to carry out maneuvering of the capsules 3 on orbit of Mars, with the purpose of docking with the locomotive 2 and maneuvering on the orbit of the Earth with the purpose of docking with the international orbital space station ISS and with tanks-containers for refuelling of chemical rocket engine 7.

Descriptions of the locomotive's design and the takeoff-landing capsule's design are given below.

The launch of space train no. 2 is carried out immediately after the freight train No. 1 has delivered into Mars orbit tanks-containers with working substance, i.e. 150 days later after the beginning of train no. 1 movement.

Let us consider the formation process of space train No. 2, which is carried out in automatic mode. At first into circumterrestrial orbit, while using carrier rocket "Delta 4 Heavy", the locomotive 1 is placed. The orbit, along which moves the locomotive 1 , should be close to the orbit of international space station ISS. After launch of locomotive 1 and its entering into the orbit, the unfolding of solar panels is carried out.

By means of the second launch, the locomotive 2 of trains no. 2 is put into the same orbit around Earth. Solar battery panels of locomotive 2 are unfolding and electric rocket engines 4 of locomotive 1 and electric rocket engines 5 of locomotive 2 are switched on.

Moving along the orbit towards each other, the locomotives 1 and 2 are approaching.

Then the docking of the locomotives 1 and 2 is carried out (with the help of the docking unit 6).

Using the carrier rocket Delta 4 Heavy, takeoff-landing capsule 3 is put into the circumterrestrial orbit, along which moves the space station ISS.

After entering into the orbit, takeoff-landing capsule 3 using chemical rocket engine 7 moves towards a free moorage of ISS. Using the docking unit 9, taxiing and docking of the capsule 3 with the ISS moorage is carried out (in automatic mode).

Five days before that the delivery of tourists and driver-astronaut on the ISS is carried out, with the help of rocket "Falcon 9".

The boarding into the train is carried out: the cruise group passes from the station ISS into cabin of capsule 3 and driver-astronaut takes his place by the control panel.

Using chemical rocket engine 7 the capsule 3 pushes off from the moorage of station ISS and moves to the orbit, where the tandem of locomotives 1 and 2 is. After approaching to locomotive 2 the takeoff-landing capsule 3 is docked with the locomotive 2, using the docking unit 8 located along its axis.

Concatenated passenger space train No. 2 departs for the cruise.

The space cruise consists of six stages. The first stage is the movement of train between the orbit of Earth and the orbit of Mars. The second stage-refuelling of the train with working substance on the base no.1 on the orbit of Mars. The third stage-landing habitable capsule onto the surface of Mars. The fourth 
stage-hiking, trips and travels along surface of Mars. The fifth stage-takeoff of the habitable capsule from Martian surface. The sixth stage-the movement of train between the orbit of Mars and the Earth's orbit.

At the first phase of the movement the driver-astronaut switches on the electric rocket engines 4 of locomotive 1 and the electric rocket engines 5 of locomotive 2. Space train No. 2 begins to gain speed. After reaching the escape velocity the train goes onto the calculated interorbital trajectory. Undoubtedly, it will be interesting for tourists to view the Moon from close range. So driver-astronaut directs the train in direction of the Earth satellite.

Two days later the train approaches Moon. It is moving at a distance of 1000 $\mathrm{km}$ from the lunar surface. Passengers are reviewing the lunar surface with a telescope.

The movement towards Mars is being continued. It occurs along the calculated trajectory.

As it already was mentioned, the calculation is carried out using the astrodynamical program, which determines the strength of the interaction between space train and bodies located in the planetary solar system [21]. Changing of the basic characteristics of train movement can be traced back at Figure 3 .

Acceleration of the space train up to speed of $100 \mathrm{~km} / \mathrm{s}$ takes place during 20 days.

During this period, due to continuous consumption of working substance, mass of the train decreases to 42 tons. On the second path section the train moves at a constant speed of $100 \mathrm{~km} / \mathrm{s}$ within 3 days, while its mass remains constant. At the end of the movement by inertia the train enters on the section of braking. In order to carry out the braking process, the train must perform a maneuver. The driver-astronaut switches on electrorocket engines 4 of locomotive 1 and train makes the turn at $180^{\circ}$. After the turn direction of thrust vector of electrorocket engines 4 and 5 is changed at 180 degrees. The driver switches electrorocket engines 4 and 5 at full power. Space train slows down speed, continuing to move toward Mars orbit. The movement of the train at the section of braking takes 18 days. The train mass is reduced to 32 tons.

38 days later after the start of the cruise, space train No. 2 goes into orbit around Mars. Trajectory of the space train movement is shown in Figure 4.

It should be reminded that Earth orbit is located at a distance of 150 million $\mathrm{km}$ from the Sun, and Mars orbit-at a distance of 230 million $\mathrm{km}$. And one revolution around the Sun, Mars carries out for 677 days. The initial position of planets on their orbits is fixed at point $\mathrm{O}$ on the Earth orbit and at point $\mathrm{O}^{\prime}$ on Mars orbit. After 38 days of movement the space train shifts from point $\mathrm{O}$ on Earth orbit into point 1 on Mars orbit. The second stage of the space cruise begins. It should be reminded, that at this time on Mars orbit at a distance of 100 $\mathrm{km}$ from its surface base no.1 moves, where tank-container with working substance-liquid nitrogen is located. The refuelling process of cryogenic tanks of locomotive 1 and locomotive 2 begins (Figure 2). To this purpose the space train 


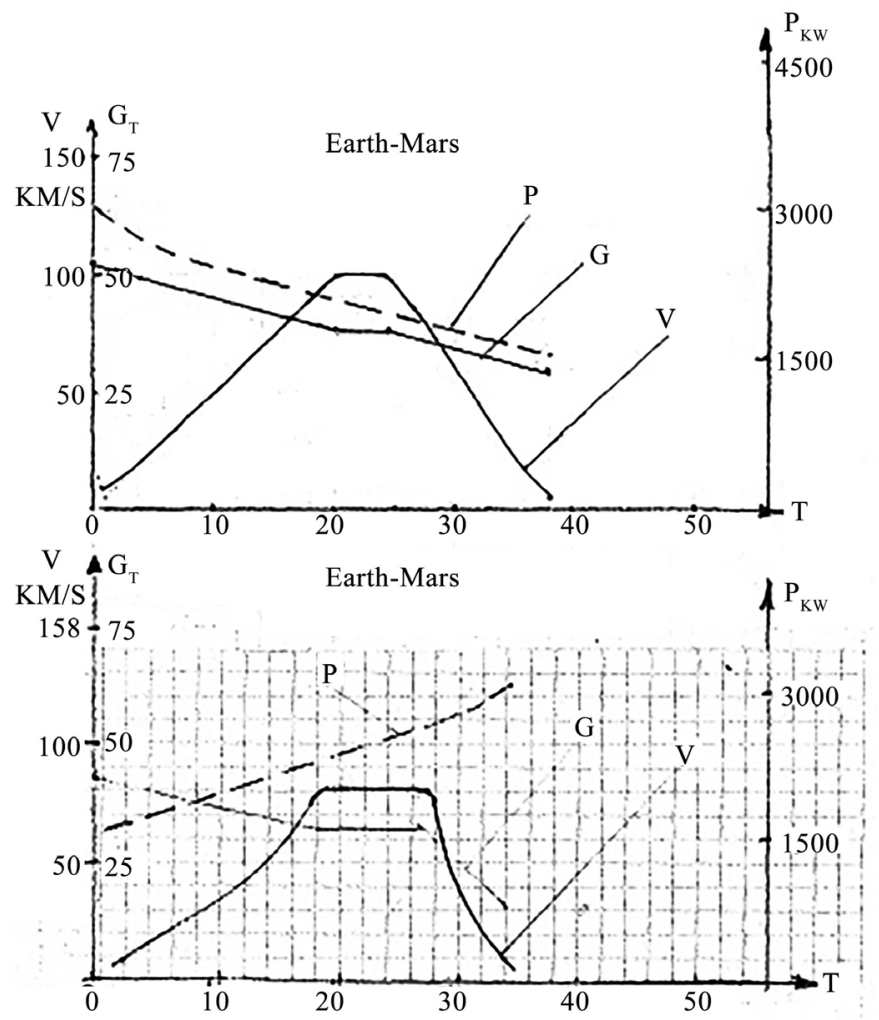

Figure 3. Basic characteristics of passenger train movement.

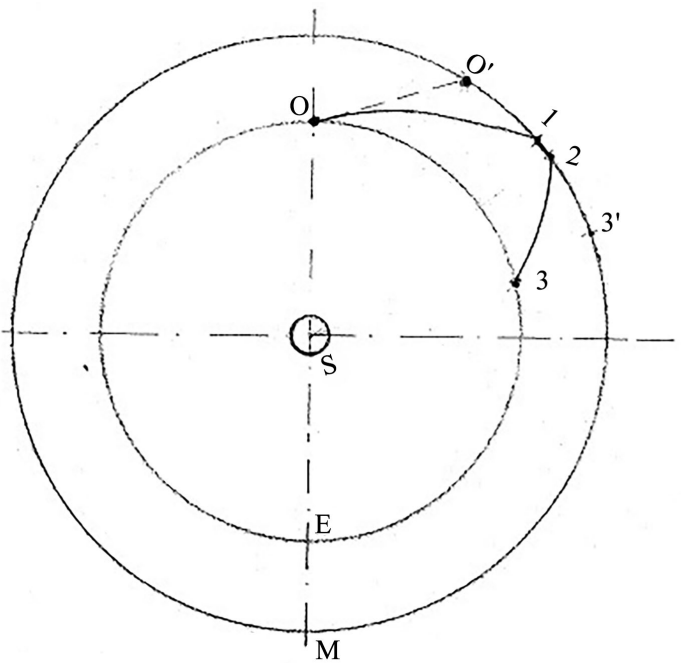

Figure 4. Trajectory of the space train No 2 movement.

becomes unlinked using docking units 6 and 8 . The driver-astronaut being located in the cabin of takeoff-landing capsule, switches on chemical rocket engine 7 of the capsule, and it departs from locomotive 2. After switching on the electric rocket engine 4 locomotive 1 starts movement towards the tank-container with working substance and takes the position shown in Figure 1.

In the automatic mode the approaching and docking of the locomotive 1 and tank container 2 is carried out. After docking the cryogenic pump, located at the 
inlet of the cryogenic tank inside the locomotive 1 is switched on and liquid nitrogen is pumped from the tank-container 2 in cryogenic tank of locomotive 1. After finishing of refuelling locomotive 1 using electrorocket engine departs from the refueling tank-container. Driver switches on electrorocket engine 5 of locomotive 2 .

Locomotive 2 is approaching to tank-container and docks with it. The operation of refilling with liquid nitrogen of cryogenic tank in the locomotive 2 is repeated. After finishing of refueling locomotive 1 connects to locomotive 2 using a docking unit 6 .

Landing of takeoff-landing capsule onto Mars surface begins. Driver switches on chemical rocket engine 7. The takeoff-landing capsule is reducing speed of movement. When the speed reaches the magnitude $3.7 \mathrm{~m} / \mathrm{sec}$, the capsule under gravity rushes towards Mars surface.

When entering the atmosphere of Mars the braking parachute system is being switched on. Owing to joint action of parachutes and chemical rocket engine, the soft landing of the capsule in the selected area on the surface of Mars, is carried out.

After the landing the most interesting phase of the cruise is being begun. Tourists clothe soft spacesuits and go into the surface of Mars. To move along the surface they use Martian rover, which has build-up structure. Movement of the Martian rover is carried out by using the electromotor, which feeds by a battery pack. The company, which organizes and serves the cruise, develops a special program for every day of stay on Mars surface. The main part of the program is an excursion along Mars surface.

After finishing of this program fulfillment, tourists take their places in the cabin of takeoff-landing capsule. Driver switches on chemical rocket engine 7. Takeoff-landing capsule starts to move vertically and when it reaches the Martian orbital velocity and goes into circular orbit around Mars. Towards the capsule the space train consisting of two jointed locomotives 1 and 2 is moving. After the approach and docking of the capsule with locomotive, the space train no. 2 is ready to the last sixth stage-movement from Mars orbit towards Earth orbit.

But before tourists are awaited by another interesting event—an approach and flying past Mars satellite-Fobos. Driver switches on electric rocket engines 4 and 5 and the space train is moving away from Mars in the direction of Fobos with speed of $4.5 \mathrm{~km} / \mathrm{s}$.

One hour later after the beginning of the movement the train is flying past Fobos at distance of $500 \mathrm{~km}$. Then driver switches the electric rocket engines at full power. Power of electromotor corresponds to power of solar batteries. Due to changes in the distance to the Sun power of solar batteries varies in time, as shown in Figure 3.

Electric power of the train on Mars orbit is equal to $1600 \mathrm{~kW}$. Let us turn again to the calculated trajectory of cruise shown at Figure 4. During stay of tourists on Mars surface the planet has passed over its orbit around the Sun from 
point 1 to point 2 .

Further movement of the train is going along trajectory from point 2 on Mars orbit to point 3 on the orbit along which the Earth moves around the Sun.

Train movement characteristics along the interorbital trajectory can be traced at Figure 3.

During 20 days the train is accelerated up to speed $80 \mathrm{~km} / \mathrm{s}$ and its mass is reduced from 42 tons to 32 tons. Then the train engines are switched off, and within 8 days train is moving at a constant speed.

28 days later after start of the movement the driver-astronaut using electrorocket engine 4 makes a maneuver resulting in $180^{\circ}$ turn of the train. It is necessary in order to change the direction of the vector traction engine in braking mode of the train.

Braking of the train begins and during 6 days its speed is reduced from 80 $\mathrm{km} / \mathrm{sec}$ to $10 \mathrm{~km} / \mathrm{s}$, mass is reduced to 15 tons, and electric power of solar batteries increases up to $3200 \mathrm{~kW}$, as shown in Figure 3.

At the thirty-fourth day of the movement between orbits the train is approaching to the Earth orbit. While its speed is $9 \mathrm{~km} / \mathrm{s}$ it goes into the designated Earth orbit.

Using the docking unit 8 separation of the train occurs (Figure 2).

Locomotive 1 and locomotive 2 connected with help of docking unit 6 are being moved (in automatic mode) using rocket engines 4 and 5, into circumterrestrial orbit, where the base no. 2 is located.

To the time of train no. 2 arrival at base no. 2 there was delivered already tank-container with liquid nitrogen. Locomotives 1 and 2 alternately dock with the tank-container and are refueled by liquid nitrogen.

After refueling locomotives 1 and 2 of passenger train no. 2 remain in orbit of base no. 2 , in pending of the space train formation for next cruise.

And now the hour of the cruise completion comes. Driver switches on chemical rocket engine of takeoff-landing capsule 7.

The capsule is approaching to a moorage of ISS and docks with the station using docking unit 9. Tourists and driver leave the takeoff-landing capsule and come in the disposal of the doctors and health care workers serving the cruise.

So the space cruise over the route "Earth-Mars-Earth", which lasted 77 days, ends.

For fulfillment of the second cruise it is necessary to refuel chemical rocket engine of takeoff-landing capsule with fuel and oxidant.

Takeoff-landing capsule in automatic mode undocks from orbital station ISS and moves towards circumterrestrial orbit of space base no. 2 . Then the capsule at first docks tank-container with liquid hydrogen and is refueled with fuel. Maneuvering with the help of chemical rocket engine 7 the capsule then docks the tank-container with liquid oxygen.

After refueling the capsule returns onto the ISS orbit and docks one of its moorages.

After carrying out routine maintenance on the takeoff-landing capsule, pas- 
senger train No. 2 is ready to the next cruise.

But one should not forget that speeds of angular movement of Mars and Earth relative to the Sun differ almost in 2 times.

Therefore the distance between the planets is constantly changing. Favorable period for cruising is the so-called period of opposition, which is observed once in two years.

By designing of the cruise, a calculated study was made concerning the possibility of conducting multiple cruises one after the other, the results of which are shown in Figure 5.

At Figure 5 the movement trajectories of the space train, when performing two successive cruises, are shown. Pause between the cruises is reduced to 5 days.

At Figure 5 main characteristic tendency for carrying out series of cruises can be traced-the increased distance at movement along the trajectory of reverse movement from Mars orbit to Earth orbit (distance between points 2 and 3). The calculation results of the second cruise duration are shown at Figure 6.

As one can see from Figure 5 the distance 0'-1' between planets along movement trajectory in comparison with the first cruise has decreased. Therefore maximum movement speed is $75 \mathrm{~km} / \mathrm{s}$. When driving along trajectory Mars-Earth the process of train acceleration up to speed of $80 \mathrm{~km} / \mathrm{s}$ is delayed up to 22 days because of solar battery power decreasing.

After the inertial movement within 14 days, the train is braked. In this case, 77 day duration of the cruise can be kept.

For the third cruise fulfillment, when the distance along backward trajectory Mars-Earth (between points 2" and 3") grows substantially, a new technical solution for space train structure, which is shown in Figure 7, has been developed.

It should be recalled that during the third cruise the space train No. 1 (Figure 1 ) is in orbit around Mars, where it has delivered the working substance-liquid nitrogen.

Locomotives 1, 2 of space train no. 2 are also arriving on the base no. 1, where it is supposed to conduct refueling with working substance.

This allows to form the new combination of space train, shown in Figure 7.

The space train for movement from Mars orbit to Earth orbit has three serially docked locomotives 1, 2 and 4. Takeoff-landing capsule is docked with locomotive 2. In such combination of the space train power supply increases in 1.5 times and amounts to $4800 \mathrm{~kW}$. And at that only the electric rocket engines of locomotives 1 and 2 are used. The locomotive 4 is in passive mode. It is only necessary for usage its solar batteries.

Therefore the tank 5 with working substance of locomotive 4 is not filled with liquid nitrogen.

The calculation results of the space train movement during the third cruise are shown in Figure 8.

When moving along trajectory Mars-Earth the space train speed is increased 
up to $120 \mathrm{~km} / \mathrm{s}$ and then within 20 days the movement is being continued by inertia.

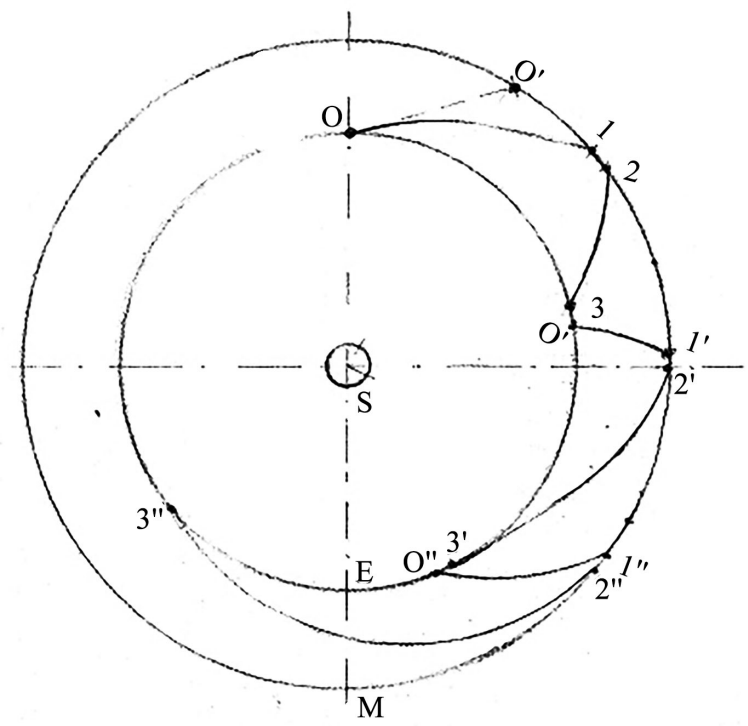

Figure 5. Calculated study of multiple cruises conducting.

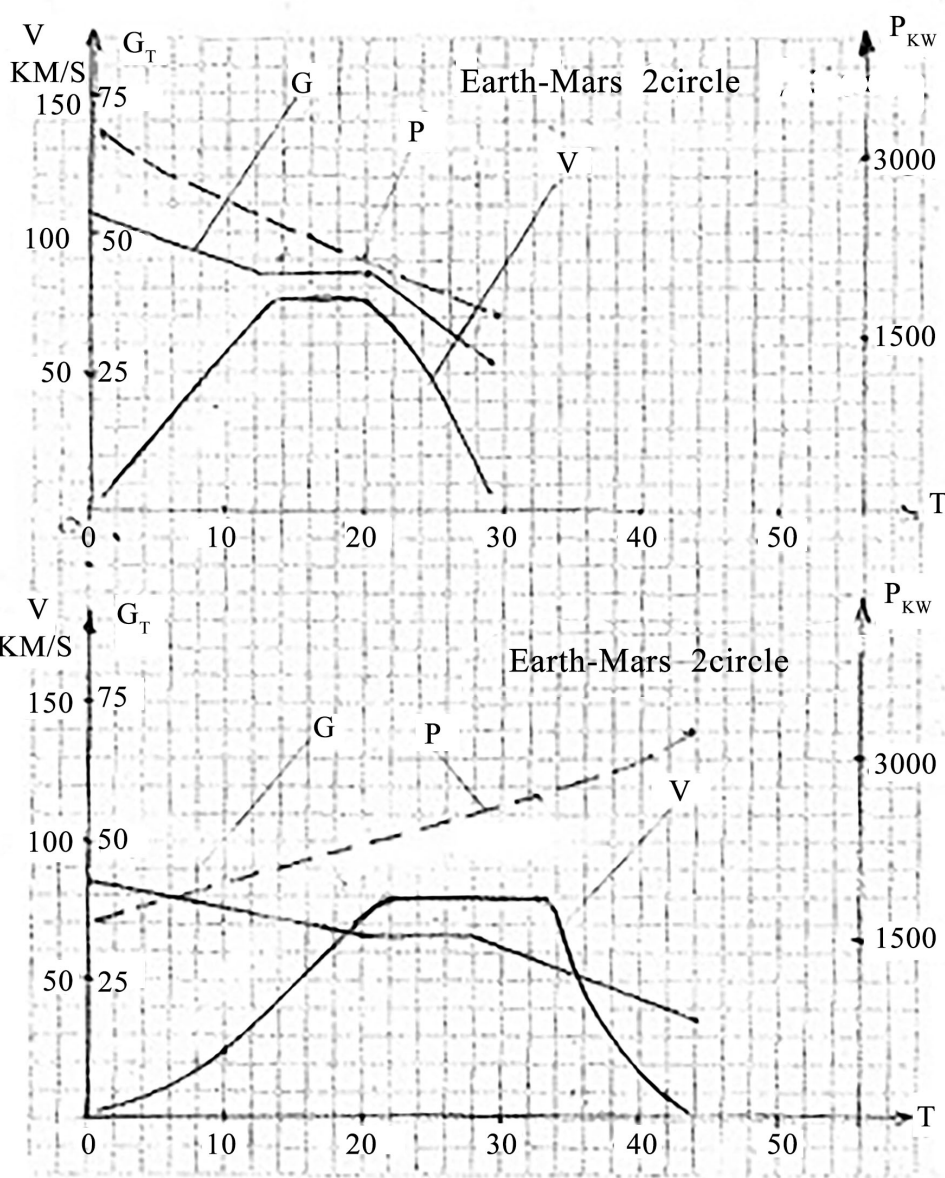

Figure 6. Calculation results of the second cruise duration. 


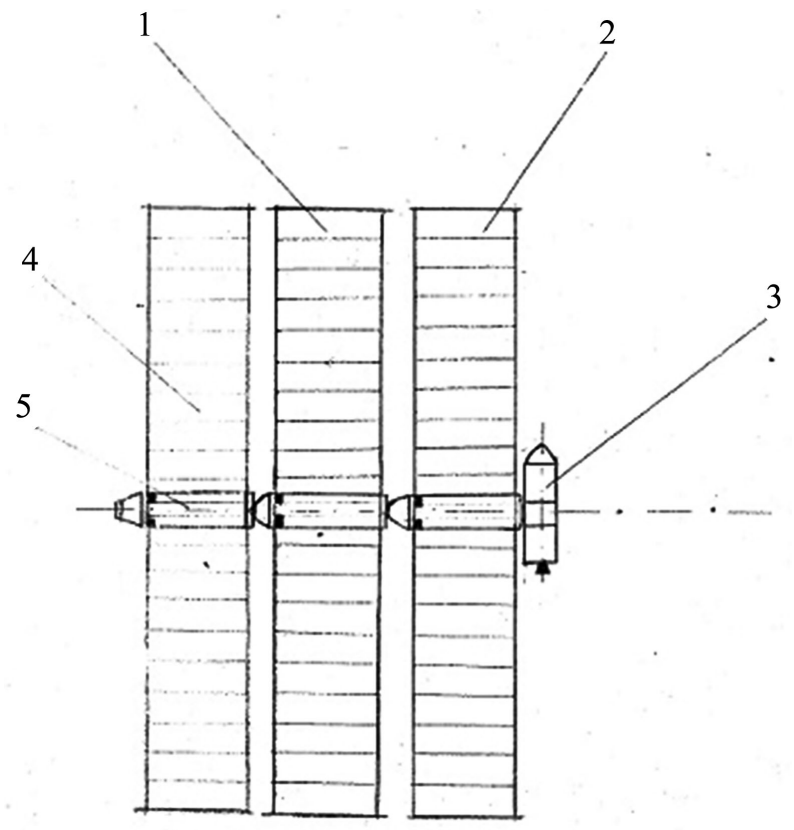

Figure 7. Structure of space train for the third cruise fulfillment.

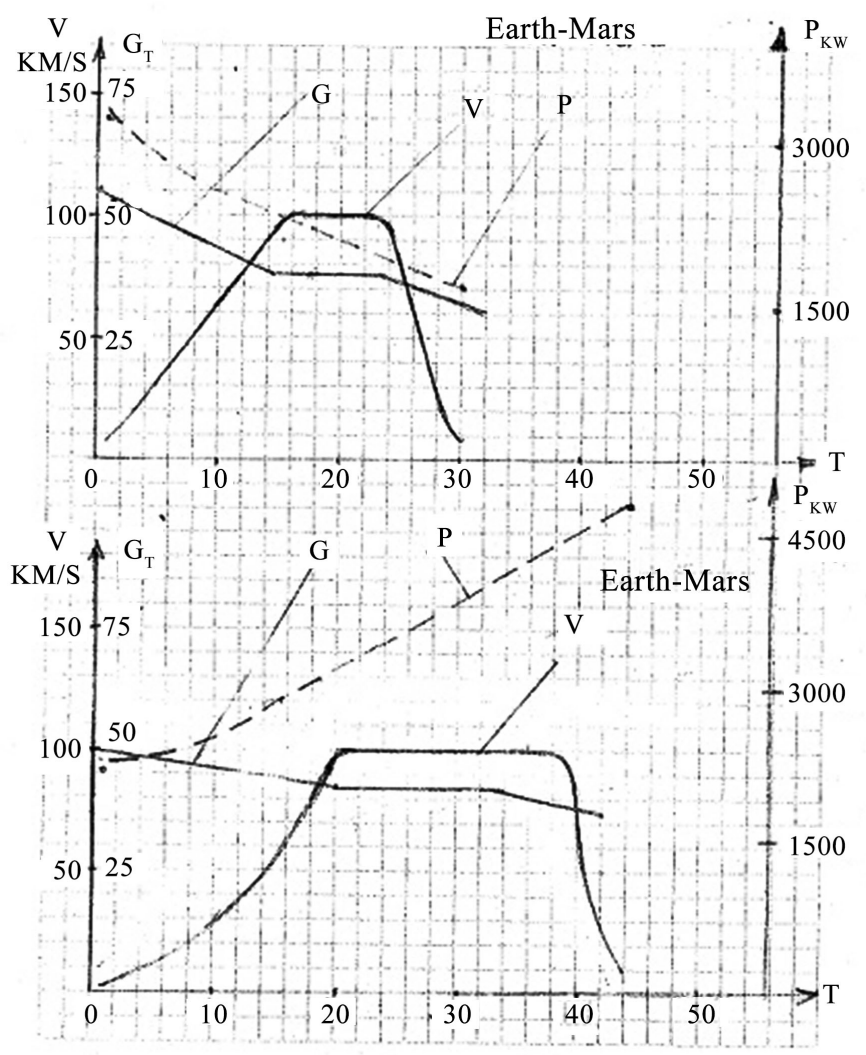

Figure 8. Space train movement during the third cruise.

After the $180^{\circ}$ degree turn, speed of the train within 4 days is decreased up to $10 \mathrm{~km} / \mathrm{s}$. As a result, and the third cruise can be also carried out within 78 days.

The space cruise over the route "Earth-Moon-Earth". 
In order to carry out the fourth cruise to Mars it is necessary to wait until Mars and Earth are approaching to a distance of no more than 200 million $\mathrm{km}$. This will happen only 18 months later after the third cruise. This rather large temporal pause is proposed to fill out by the fulfillment of another space tourist commercial event, because all the equipment, which was used when conducting Martian cruises: locomotives, tanks-containers for refilling and takeoff-landing capsule, after the third cruise remains in Earth orbit.

Calculations have showed that this equipment can be used for a series of additional commercial events-tourist cruises on the Moon.

One can safe to assume that those who wishes to visit the Moon will be enough. After all, duration of the travel to the Moon as compared to travel to Mars is much smaller, the cost will be much less, and emotional load is not much weaker.

Structural schema of space train for cruise over the route: Earth orbit-the Moon-Earth orbit, is shown at Figure 9.

The space train consists of locomotive 1 with solar battery panels and electrical rocket engines 3 and takeoff-landing capsule 2.

The first cruise to the Moon can be carried out 14 days later after the end of the third cruise to Mars.

The cruise to the Moon begins with fueling of space train engines (Figure 9) with working substance-liquid nitrogen, which is carried out on the base no. 2 .

And at the same time on the base no. 2 the takeoff-landing capsule comes (in automatic mode). Refueling of tanks with liquid oxygen and liquid hydrogen, which are necessary for chemical rocket engine 4 operation of the capsule, is carried out.

After the refueling the takeoff-landing capsule again is docking to a moorage of the international space station ISS.

10 tourists and the driver-astronaut are taking places in the cabin of takeoff-landing capsule. The driver switches on chemical rocket engine, and the capsule pushes off the moorage of station ISS. Then the capsule goes into orbit, where locomotive 1 is.

After approaching and docking driver switches on electric rocket engines 3 of locomotive 1 and the space train no. 3, shown in Figure 9, starts to move along the calculated trajectory: "Earth orbit-Moon orbit".

After 20 hours of the movement the train acquires the escape velocity and leaves the Earth's orbit. 1 day later the train speed reaches $15 \mathrm{~km} / \mathrm{sec}$. After $180^{\circ}$ turning, driver is putting the train in braking mode. 4 days later train speed decreases up to orbital velocity and the train goes into orbit around the Moon.

The second stage of the cruise Earth-Moon begins. The space train (Figure 9) is divided using docking unit 5 . Takeoff-landing capsule, being controlled by the driver commits a soft landing on the lunar surface. Tourists go out onto the Moon surface. Programme of activities during the stay on the Moon is reckoned for 5 days. 


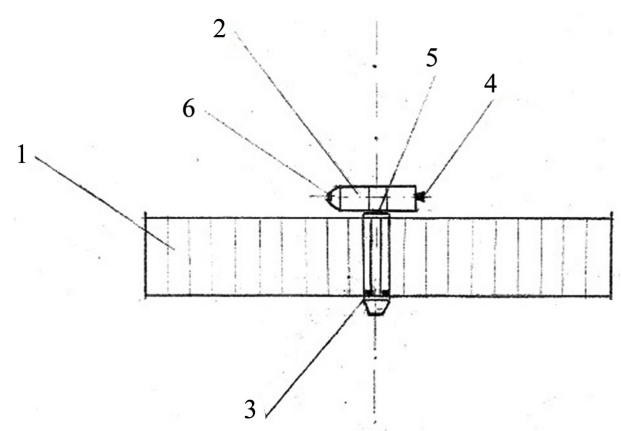

Figure 9. Space train for cruise over the route: Earth orbit-the Moon-Earth orbit.

During the first days, tourists are learning to move on the surface of the Moon and are carrying out assembling of Martian rover. Then the trips across the Moon surface using rover begin. After completion of the program stay on the Moon surface, the tourists are taking their places in takeoff-landing capsule.

Driver switches on chemical rocket engine and the capsule carries out vertical take-off from the Moon's surface and goes into orbit around the Moon. Locomotive 1 which is on the Moon orbit, is taxiing to the capsule and docks with it. During the last phase of the train movement electric rocket engines are switched at full power.

25 minutes later the electric train leaves the lunar orbit and begins movement toward the Earth.

After acceleration and braking, the train 6 days later goes into orbit around the Earth. Using the docking unit 5 the train is divided and locomotive 1 departs from the capsule 2. Driver switches on chemical rocket engine 4, capsule makes a maneuver and goes into orbit of ISS station. After approaching to ISS, the capsule 2 docks to a moorage of ISS, using docking unit 6 . In such a way the cruise Earth-Moon, which lasts 17 days, ends. After the necessary pause (14 days), the carrying out of the cruises Earth-Moon continues.

Calculations show that the fuelling of electrical rocket engines with liquid nitrogen should be carried out after 5 lunar cruises and the fuelling of chemical rocket engines of capsule with liquid hydrogen and oxygen-after 3 cruises. The project makes it possible during 2 years to conduct 3 cruises on the Mars and 15 cruises on the Moon.

\section{Cost of the Cruise}

In order to determine the cost of cruises over the route Earth-Mars-Earth the calculations of capital costs and operating costs were performed. The largest capital costs are necessary for development and production of solar cell based on gallium arsenide. Works on the cost reducing of gallium arsenide panels are conducted in the laboratories of several universities in United States. According to the Agency "Pulsar" in May 2016 the specialists of the University of Illinois under the leadership of John Rogers have developed a new manufacturing tech- 
nology, which has made it possible to reduce the cost to the level of 1 dollar for 1 Watt.

For operation of three locomotives, which are used when fulfillment the cruise, it is necessary to have three solar batteries providing total power 4800 $\mathrm{kW}$.

Calculations have shown that the cost of three locomotives will be 30 million dollars and cost of takeoff-landing capsule can be at the level of 20 million dollars.

Taking into account the cost of tanks-containers required for fueling electrical and chemical rocket engines, the capital costs for production of the electrical rocket train will amount to 70 million dollars.

In order to deliver 3 locomotives and takeoff-landing capsule into Earth orbit by means of carrier rockets Delta 4 and Falcon X Heavy it is necessary to expend 400 million dollar.

An analysis of operating costs when performing of the cruises had showed that the lion's share of the costs will be costs for transportation of tourists onto international space station ISS and back to Earth. Today it is carried out using carrier rocket Soyuz- 2 and the cost for delivery of one person amounts 20 million dollars. It should be recalled that the first space tourist Dennis Anthony Tito in 2001 year has paid exactly this amount for the flight to Earth orbit.

In this regard, the works which were performed during the past few years by the company "Space X" for creation of the new carrier rocket "Falcon", the first stage of which can be used iteratively, resulting in the substantial reduction the cost of launching, are of great interest from the point of view of space tourism.

In the coming years, one should expect the beginning of regular flights of the Falcon 9 to the international space station ISS. Space capsule "Dragon V2" will deliver 7 astronauts into Earth orbit [22] [23]. One should expect reduction the delivery cost of space tourists to the ISS station at least in twice.

The calculations have shown that operational costs for fulfillment of the cruises will amount for 2.2 billion dollars.

As it is known, the implementation of the business plan of an enterprise requires market research. In this case it will be especially difficult task, which solution depends in larger extent on sociologists and psychologists than on economists and engineers and, of course, the implementation of this enterprise can be begun only after a positive answer to the question about its profitableness.

Space locomotive

The space locomotive, which has housing 1 of cylindrical form, located along the axis of the locomotive, is shown at Figure 10.

On both sides of the housing, two wings of solar panels 2 and 3 are located, which are the photoelectric transducers based on gallium arsenide.

The solar panels are designed for electricity supply of electrical rocket engines 4.

The connection of the housing 1 and wings 2 and 3 of solar panels are made using the external end discs 5 and 6 . In the disk 5 , which is located in the fore 
part of the locomotive, electrical rocket engines 4 are installed. In the disk 6, which is located in tail part of the locomotive, the superconducting bearing is installed together with external docking unit 8 which is intended for joining of the locomotive with takeoff-landing capsule.

In the inner part of the cylindrical housing 1, along the horizontal axis, a cryogenic tank with working substance-liquid nitrogen, is installed.

In the fore part (at the very butt end of the cylindrical housing) the docking unit 7 , is located through which during refueling the locomotive is connected with refueller of liquid nitrogen (Figure 1).

Design of locomotive housing and its connection with the solar battery panels is shown at Figure 11.

The solar panel has folding design. It is assembled from separate panels 4 and is arranged like a folding Chinese screen. The panel 4 is made from carbon-filled plastic, in which from the outside a layer of photoelectric converter from the gallium arsenide is being sealed. The panels 4 are joined to each other using hinges $16,17$.

First such a design of solar battery was proposed by author when designing "Venus plane"-the apparatus for continuous flight in the atmosphere of Venus [8].

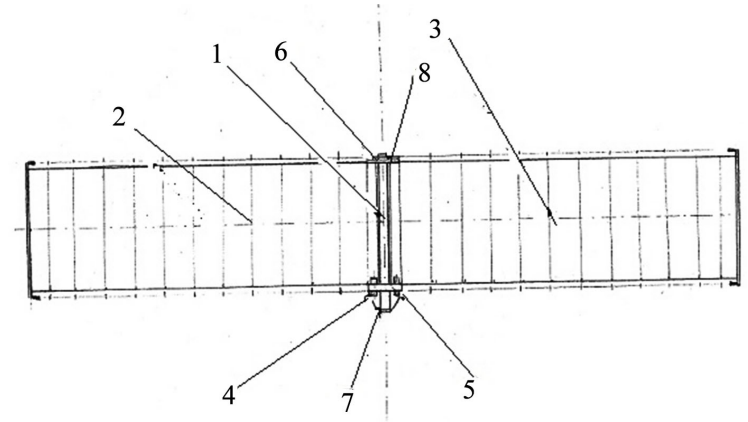

Figure 10. Space locomotive.

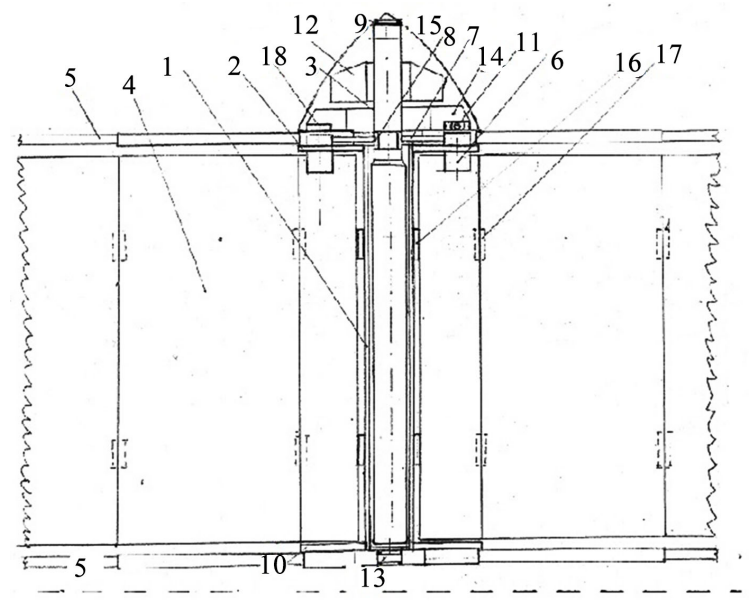

Figure 11. Locomotive housing and its connection with the solar battery panels. 
As constructive basis serves cylindrical housing of the locomotive 1 , which is made of aluminum alloy.

In Figure 11 the fore disk 2 as well the tail disk 10 are shown.

In the internal cavity of the housing 1 the tank 3 with liquid nitrogen is installed. In order to minimize evaporation losses, the tank 3 is manufactured of carbon and has screen-vacuum insulation.

For the implementation of locomotive refueling on orbits of the Mars and the Earth in the end face of cryogenic tank the docking unit 9 is installed with the device for feeding of liquid nitrogen inside the tank 3 .

The device complex for feeding of liquid nitrogen in cryogenic tank contains a cryogenic pump 8, which design is described in [10].

The developed solar panels 4 have two positions: the folded position (when delivering into Earth orbit) and the unfolded position for electricity production. The solar panel in the folded position is shown in Figure 12.

The solar panels 2 are connected with housing 1 while using the hinges 3 . External solar panels have longitudinal beams 5 and 6. From the outside the structure of the solar panel is sustained using a cylindrical shell 4, while the longitudinal beams 5 and 6 are fastened on inner surface of the cylindrical shell 4 . To install the solar panels in working position (perpendicular to the horizontal axis of the locomotive) the sliding rods (shown in Figure 11 under index 5) installed on both sides are used. The sliding rods 5 are fastened on the outside of the end discs 2 and 10. The sliding rods are performed in the form of concentric cylinders being inserted each into other. It is similar to the design of telescopic antennas used in portable radio receivers.

From the locomotive housing side the sliding rods are joined with longitudinal beams 5 and 6 (Figure 12). In course of solar panels unfolding, the external shell 4 (Figure 12) is being thrown off.

The unfolding of the panels is carried out by means the feeding of gaseous nitrogen (under pressure) inside telescopic system 5 (Figure 11). During this process the beams 5 and 6 are moved along transverse axis and bring the design of solar panels into the working state, as shown in Figure 10.

The location of sliding rods and the electric rocket engines relative to the housing of the locomotive is shown in Figure 13.

The end disk 2, which is fastened on cylindrical housing 1, has four holes angled $90^{\circ}$.

Hole 4 diameter corresponds to the outer diameter of electric rocket engine.

The cryogenic tank with liquid nitrogen located on the longitudinal axis of the locomotive and the sliding rods of solar panels 6 and 7 located along the transverse axis are shown in cross-section.

The locomotive of space train, together with the solar cell, has stand-alone control system.

Equipment of the control system is placed in the container 12 in the nasal part of the locomotive, as shown in Figure 11. 


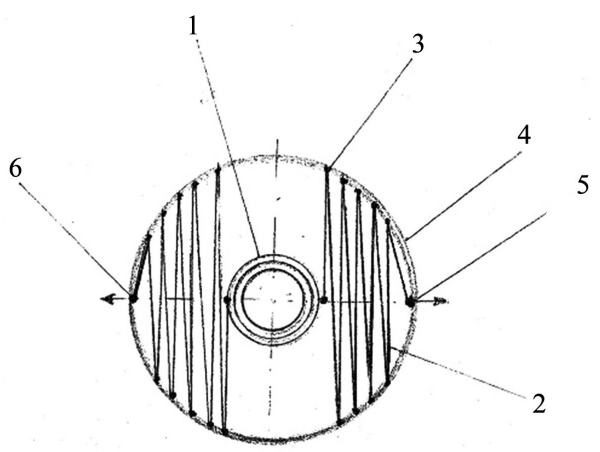

Figure 12. Solar panel in folded position.

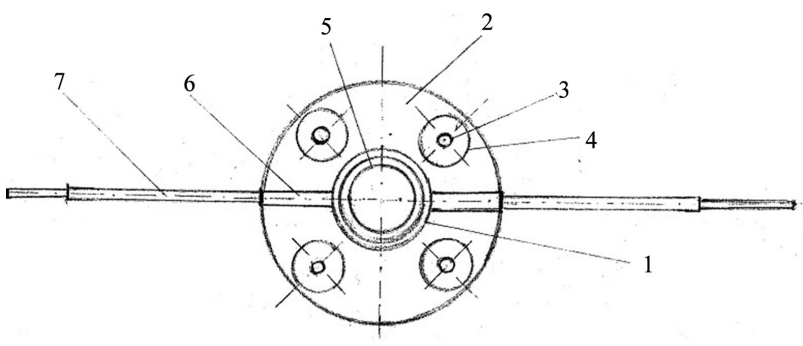

Figure 13. The location of sliding rods and the electric rocket engines.

Change of the locomotive movement direction-pitch and yaw is carried out by changing traction force of engines 6 , which cryostats are continuously supplied with working substance-liquid nitrogen. Changing of traction force is carried out by change of the engine amperage using a power transistor. The rotation of the locomotive is provided by creating torque relative the axis. To this purpose a low-thrust electric rocket engine 11 is being installed on periphery of the end disk 2. This electric engine, which creates tangential traction $10 \mathrm{~N}$, provides $80 \mathrm{~kW}$ of capacity.

The block 14 for control of locomotive movement is being installed at the end of disc 4.

The electric rocket engine 11 is the executive organ of the system 18, which is installed on the end disk 2 and is intended for permanent tracking of the Sun position. The system 18 determines the angle of rotation of locomotive relative to axis, when the solar battery panel is producing maximum power.

In the rear of the locomotive superconducting bearing and the docking unit 13 are installed, which provide rotation of the docked takeoff-landing capsule, creating artificial gravity in cabins for tourists.

The design of the superconducting magnetic bearing, which is working on Meissner effect, is described in [12].

\section{Superconducting Electric Rocket Engine "MARS"*}

Design of the superconducting electric rocket engine "MARS"* is shown at Figure 14 (longitudinal section) and at Figure 15 (cross-section). 


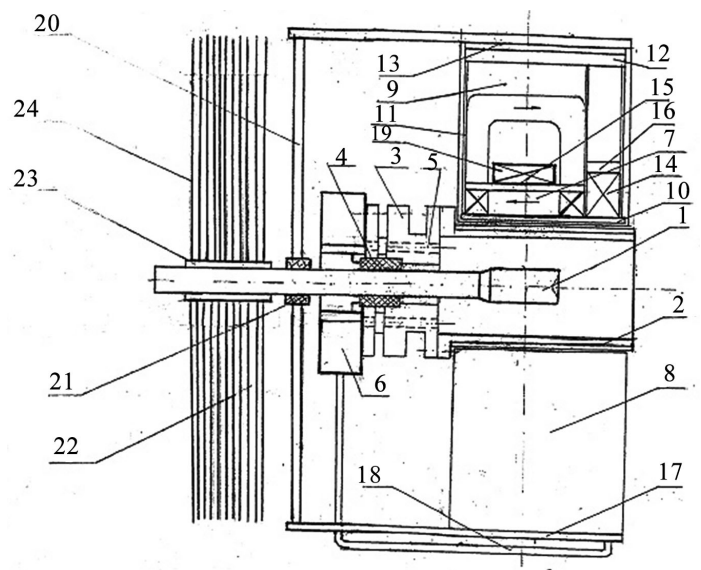

Figure 14. Superconducting electric rocket engine "MARS" (longitudinal section). *Abbreviation of the engine name in German language: Motor für die Allrakete mit der Supraleitung.

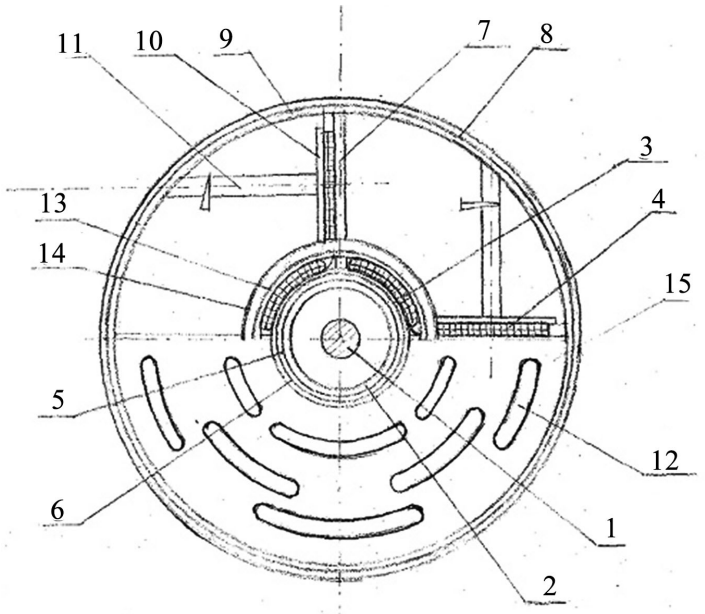

Figure 15. Superconducting electric rocket engine "MARS"^ (cross section).

According to the principle of operation it belongs to the class of magnetoplasma electric rocket engines with external superconducting excitation winding.

In the working chamber of the engine there are cathode 1 (located along engine axis) and anode 2 (on outside of the cathode), which both have cylindrical form.

The cathode 1 is fastened on the anode 2, using a cylindrical bushing 3 and an isolator 4 which has the shape of cylinder too.

As working substance the engine uses nitrogen which is fed in gaseous state into interelectrode space via channel 5 in sleeve 3 . Gaseous nitrogen is fed via the pipeline 18 into the camera 6 of working substance preparation, which has a ring shape.

Inside the camera 6 there are a doser and a solenoid valve.

Anode 2 is installed and fastened in cylindrical cavity of the cryostat 8 , which 
is made of carbon and where also the superconducting magnetic system of the engine is located.

The superconducting magnet system consists of three windings intended for different purposes. The first winding 7 consists of four coils, creating the tangentially directed magnetic field in the working chamber of the engine. The second winding 14 has cylindrical shape. It plays the role of a magnetic nozzle and compresses working substance, which in plasma state is thrown out of the working chamber. The third winding 19 has cylindrical shape and is designed to stabilize an electric arc between the electrodes 1 and 2 by means its uniform rotation.

As it can be seen in Figure 15, the coil of the first winding consists of two parts 3 and 4 . The part 3 of the coil, which semicircles are coiled in the forward direction, is placed on the outer surface of the cylinder 6. By forming this part of the coil 3 before laying acquires form of cylinder.

The other part of the coil 4 with semicircles coiled in the opposite direction is unbend and is laid along radius. In the similar way laying of the other three coils of the first winding is made.

The coils fastening of the first winding is carried out using cylindrical bandage 13 and flat bandage 10 which presses the winding to the rib 7 using a coil holder 11.

The inner cavity of the cryostat, which has an external shell 9, is filled with liquid nitrogen.

The inner shell of the cryostat 5 , is located on the outside of the anode 2 .

The outer shell 9 of the cryostat when assembling of the engine is inserted inside of the cylindrical outer housing 8 .

The cylindrical outer housing (denoted by the index 17 in Figure 14) has a disk 20 in its end part which is used as a thermal bridge between the hot cathode 1 and the cold cryostat 8 . The cathode 1 is fastened in the disk 20 , using an insulating spacer 21 .

In order to reduce the thermal flow from the cathode to the cryostat some cuts in the disk 20 are made, increasing thermal resistance of the disk. On the cross-section (Figure 15) these cuts are denoted by index 12 .

Elements of the intensive cooling of the cathode 1 are shown at Figure 14. For this purpose, disk radiator 24 , which is giving the heat into outer space, is installed at the cathode surface from the side opposite to the working chamber, using the cylindrical spacer 23.

Reducing of the cathode surface temperature reduces the amount of cathode mass carryover and increases the service life of the engine.

Calculated parameters and dimensions of the engine MARS for the cruise "Earth-Mars-Earth", are shown in Table 1.

\section{Takeoff-Landing Capsule}

Design of the takeoff-landing capsule is shown at Figure 16. 


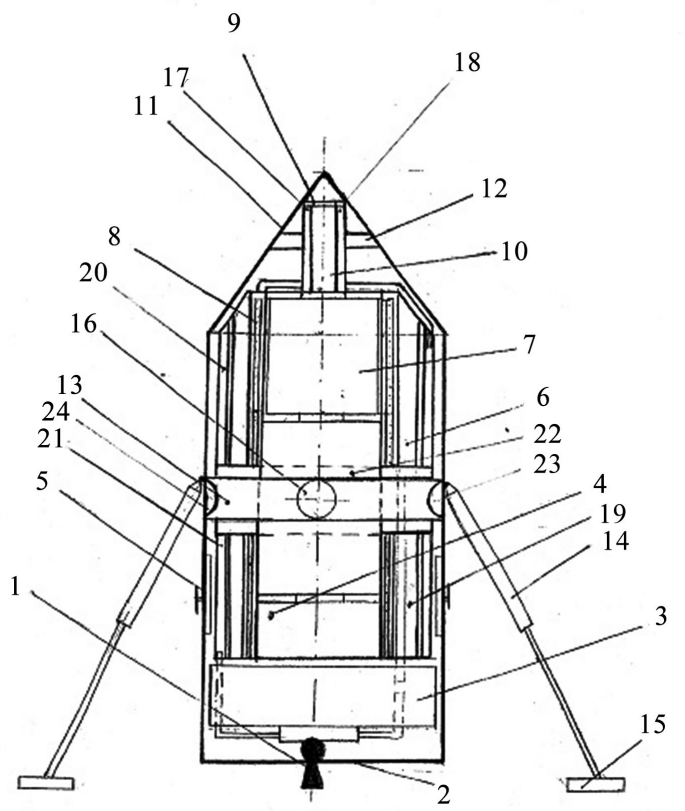

Figure 16. Takeoff-landing capsule.

Table 1. Calculated parameters and dimentions of the engine MARS.

\begin{tabular}{cc}
\hline Traction force & $60 \mathrm{~N}$ \\
\hline Power & $600 \mathrm{~kW}$ \\
Current & $600 \mathrm{~A}$ \\
Voltage & $1000 \mathrm{~V}$ \\
Efficiency & $94.5 \%$ \\
Special impulse & $6000 \mathrm{sec}$ \\
Working substance consumption & $1 \mathrm{~g} / \mathrm{sec}$ \\
Working substance outflow velocity & $10 \mathrm{~km} / \mathrm{sec}$ \\
Magnetic induction & $1.5 \mathrm{~T}$ \\
Anode diameter & $170 \mathrm{~mm}$ \\
Cathode diameter & $40 \mathrm{~mm}$ \\
Anode length & $100 \mathrm{~mm}$ \\
Cathode length & $60 \mathrm{~mm}$ \\
External cylinder diameter & $650 \mathrm{~mm}$ \\
External cylinder length & $450 \mathrm{~mm}$ \\
\hline
\end{tabular}

The capsule is an autonomous spacecraft capable to maneuver on orbit of the Earth and in orbit of Mars and to carry out landings and takeoffs from the surface of Mars. In order to do this the capsule is equipped with chemical, oxygen-hydrogen rocket engine 1.

To create traction force the chemical rocket engine $1 \times$ PWRL-10B-2-1, pro- 
duced by the firm Boeing with thrust $110 \mathrm{KN}$, is used.

Chemical rocket engine 1 is installed in end part of the cylindrical housing 2 under cryogenic tank 3, in which fuel-liquid hydrogen is stored. Besides, the liquid hydrogen is poured into the tanks 6 and 19. The hydrogen tanks 6 and 19 are made in the shape of a hollow cylinder and are located along the entire length of the capsule. From the outside of tanks 6 and 19, the hollow cylindrical tanks 20 and 21 with oxidizer-liquid oxygen, are located.

Filling of tanks 6, 19 and 3 with liquid hydrogen is carried out using the pipeline 17. Filling of tanks 20 and 21 with liquid oxygen is carried out using the pipeline 18.

The fuel tanks 6 and 19 have an internal cylindrical cavity in which the crew cabins 7 and 4 are located. Such location of the cabins is necessary in order to provide crew protection from cosmic radiation.

Cabin protection against stream of charged particles is provided by creating an external constant magnetic field. For this purpose inside the tanks 6, 19 with liquid hydrogen an electromagnet 8 is installed.

The electromagnet 8 is a cylindrical solenoid, which coil is wound by superconducting wire based on the magnesium-boron [14].

The usage of the electromagnet 8 provides protection against radiation during passing of radiation belts of the Earth, as well as from the solar wind during movement of the train in space. Protection of cabins against the galactic cosmic radiation is carried out by a layer of liquid oxygen in tanks 20 and 21 and by a layer of liquid hydrogen in the tanks 6 and 19 [12].

Boarding of the space tourists in the capsule, which is docked to a moorage of the international space station ISS, is performed via nasal docking unit 9 and tunnel 10, from which they penetrate into the cabin 7.

Between cabins 7 and 4 a salon 22 is located, which serves as club premises. Here one can get the current information about the movement of space train, communicate with colleagues and observe the outer space through portholes, 23 and 24, while experiencing the state of weightlessness.

Cabins 4 and 7 are equipped like in the module "Zvezda" ("Star") of ISS station, with the full range of amenities for long stay of 10 persons in space (beds, shower, toilet, kitchen, etc.).

In the nasal part of the capsule, which ends with cone 11, parachute system 12, which is designed to brake the capsule in the atmosphere of Mars while landing on its surface is located.

The load-bearing cylinder belt 13 which is located in the middle part of the capsule, has the opening uprights.

Soft landing is ensured through the creation of the traction force, which creates chemical rocket engine 1 .

Design of the capsule provides for the creation of artificial gravity in the cabins 4 and 7 by rotation of the capsule relative to transverse axis. For this purpose, the capsule has the second docking unit 16 . Using the docking unit 16 the takeoff-landing capsule connects with a docking unit of locomotive, in which the 
bearing, working on Meisner effect is located [5]. The position of the capsule 3 and the locomotive 2 in the docked state one can see at Figure 2. The docking unit with the cryogenic bearing 13 is shown in Figure 11.

The calculation results of the main dimensions and masses of components of electric rocket train are shown in Table 2.

\section{Conclusions}

1) For the first time, the comprehensive scientific research and engineering design of a space cruise along the route "Earth-Mars-Earth", which is implemented by the space train, consisting of a locomotive and a takeoff-landing capsule, is performed.

2) A new design of electric locomotive that combines the tank with working substance and a solar battery in one rocket launched using rocket "Delta" is developed.

3) The conducted studies have shown that the most appropriate is to put the locomotive in motion using four electrorocket engines MARS, which working substance is nitrogen.

4) A methodology for carrying out cruise with refueling tank with working substance in the orbit of Mars, allowing to cut the time of interorbital flights in twice is developed.

5) New design of takeoff-landing runway capsules, which provides maximum protection for tourists from cosmic radiation with usage of a layer of liquid oxygen and liquid hydrogen and by creating a magnetic field around cabin, is developed.

Table 2. Main dimentions and masses of components of electric rocket train.

\begin{tabular}{cc}
\hline Locomotive housing length & $25 \mathrm{~m}$ \\
Locomotive housing diameter & $1.1 \mathrm{~m}$ \\
Solar panel wing length & $6.0 \mathrm{~m}$ \\
Solar panel wing width & $60 \mathrm{~m}$ \\
Length of takeoff-landing capsule & $20 \mathrm{~m}$ \\
Diameter of takeoff-landing capsule & $18.0 \mathrm{~m}$ \\
Mass & $6.0 \mathrm{~m}$ \\
Locomotive & $19.6 \mathrm{~T}$ \\
Solar panel & $4.0 \mathrm{~T}$ \\
Electro rocket engines & $0.8 \mathrm{~T}$ \\
Lryogenic tank with liquid nitrogen & $0.8 \mathrm{~T}$
\end{tabular}


6) The results of the calculated researches demonstrate that the proposed complex of new design solutions allows to carry out during 2 years 3 cruises with landing on the surface of Mars and 15 cruises with landing on the lunar surface.

\section{References}

[1] Gabriel, et al. (1981) An MPD Transfer Test System. AIAA Paper No. 81-0688.

[2] Chouerieri, E.Y. (2011) Das Zeitalter der elektrischen Raketen. Spektrum der Wissenschaft Dossier 1/11.

[3] Rubinraut, A. (2006) Elektrischer Düsenantrieb für den Flug zum Mars. Gebrauchsmuster DE 20200600711701 DPMA.

[4] Rubinraut, A. (2008) Raumschiff der wiederverwendbaren Nutzung für den Flug zum Mars. Offenlegungsschrift DE 102008019666 A1 DPMA.

[5] Rubinraut, A. (2011) Raumschlepper für Fluge zu den Planeten des Sonnensystems Offenlegungsschrift DE 102011115997 A1 DPMA.

[6] Rubinraut, A. (2013) Elektrischer Düsenantrieb für den Flug zum Mars Patent Nr 102006022559 DPMA.

[7] Rubinraut, A. (2015) The Expedition to Mars. International Journal of Emerging Technology and Advanced Engineering, 5, 548-560.

[8] Rubinraut, A. (2017) The Expedition towards Venus. International Journal of Emerging Technology and Advanced Engineering, 7, 177-187.

[9] Rubinraut, A. (2017) The Expedition on Mercury. IJETAE, 7, 304-313.

[10] Rubinraut, A. (2016) The Expedition to Jupiter. IJETAE, 5, 283-293.

[11] Rubinraut, A. (2016) The Expedition to Saturn and Creation of a Space Base on Titan. IJETAE, 6, 1-11.

[12] Rubinraut, A. (2016) The Expedition towards Uranium. IJETAE, 6, 32-39.

[13] Rubinraut, A. (2016) The Expedition towards Neptune. Creation a System of Interplanetary Communications. IJETAE, 6, 138-148.

[14] Rubinraut, A. (2017) Interorbital Raketenträger mit Tankwart Offenlegungsschrift DE 102015014869 A1 DPMA.

[15] Rubinraut, A. (2017) The Study of the Electrorocket Engine for the Future. Advances in Aerospace Science and Technology, 2, 1-16. https://doi.org/10.4236/aast.2017.21001

[16] Rubinraut, A. (2016) Elektrisches Raketentriebwerk für Dauerweltraumflüge. Patent Nr. 102013008832 DPMA München 2016.

[17] Антон Первушин (2006)Завоевание Марса. Москва Яуза 2006. (In Russian)

[18] Astronergy APP (2017) The Power of Astronergy.

[19] Leicht, B. and Flexibel, G. (2017) Das Magazin über flexible Photovoltaiklösungen, Nummer 1/2017 Energy. Wiener Neustat, Austria.

[20] Жалнин, Б., Каган, М. and Наумов, А. (2016) Отечественная космическая энергетика: Вчера, сегодня, завтра Электроника, новые технологии №2 (00152) Москва 2016. (In Russian)

[21] Рой, А. (1991) Движение по орбитам. Мир. Москва. (In Russian)

[22] Reise zum Mars (2015) Das Weltraum Magazin Space 5.

[23] Feuerbacher, B. and Messerschmid, E. (2007) Vom All in dem Alltag. Motorbuchverlag. Stuttgart 2007. 